\title{
Chemical-Looping Combustion with Liquid Fuels
}

\author{
Magnus Rydén ${ }^{\mathrm{a}}$, Patrick Moldenhauer ${ }^{\mathrm{a},{ }^{*},}$, Tobias Mattisson ${ }^{\mathrm{a}}$, Anders Lyngfelt ${ }^{\mathrm{a}}$, \\ Mourad Younes ${ }^{\mathrm{b}}$, Tidjani Niass ${ }^{\mathrm{b}}$, Bandar Fadhel $^{\mathrm{b}}$, Jean-Pierre Ballaguet ${ }^{\mathrm{b}}$ \\ ${ }^{a}$ Department of Energy and Environment, Chalmers University of Technology, 41296 Göteborg, Sweden \\ ${ }^{b}$ SAUDI ARAMCO, Research \& Development Center, P.O.Box: 62, 31311, Dhahran, Kingdom of Saudi Arabia
}

\begin{abstract}
A project devoted to establishing chemical-looping combustion with liquid fuels currently being conducted by Chalmers University of Technology with support from Saudi Aramco is presented. The ultimate goal of the project is to develop technology capable of utilizing and processing heavy residual oils with inherent $\mathrm{CO}_{2}$ capture. Up to this point, a continuously operating reactor with the nominal effect $300 \mathrm{~W}$ has been designed, constructed, and successfully operated with nickel- , manganese-, copper- and iron-based oxygen-carrier particles using non-sulfurous and sulfurous kerosene as fuel. The results so far are very promising, and $99 \%$ conversion of fuel carbon to $\mathrm{CO}_{2}$ has been demonstrated with all four kinds of oxygen carrier materials. Chemical-looping reforming for synthesis gas production was also demonstrated using kerosene and the Ni-based oxygen carrier. Here, complete hydrocarbon conversion to $\mathrm{CO}$ and $\mathrm{H}_{2}$ was achieved. Future work includes design and construction of a larger $10 \mathrm{~kW}$ reactor system for direct combustion of heavier fuels such as fuel oil and heavy vacuum residues, as well as a technoeconomic study. This paper provides an overview of the project and presents the main results and conclusions so far.
\end{abstract}

(C) 2013 The Authors. Published by Elsevier Ltd.

Selection and/or peer-review under responsibility of GHGT

Keywords: Chemical-Looping Combustion; Liquid Fuels; Kerosene; Heavy Oil Residues

\section{Introduction}

It is by now widely acknowledged that global emissions of the greenhouse gas $\mathrm{CO}_{2}$ will need to be reduced greatly in the future and that one possible way to achieve this could be $\mathrm{CO}_{2}$ capture and storage (CCS), see for example the Intergovernmental Panel on Climate Change (IPCC) special report on the issues [1]. This paper presents results from a project devoted to establishing the chemical-looping combustion technology for $\mathrm{CO}_{2}$ capture with liquid fuels. The project is undertaken by Chalmers University of Technology with support from the world largest oil producing company Saudi Aramco. The ultimate goal of the project is to develop technology capable of utilizing and processing heavy residual

\footnotetext{
* Corresponding author. Tel.: +46 317721469

E-mail address: patrick.moldenhauer@chalmers.se
} 
oils, while at the same time providing inherent $\mathrm{CO}_{2}$ capture. Such technology could be especially valuable in oil producing countries such as Saudi Arabia where oil is used for power generation and a future $\mathrm{CO}_{2}$ demand could be expected for enhanced oil recovery (EOR), see Liu et al. [2].

\section{Background}

\subsection{Chemical-Looping Combustion}

Chemical-looping combustion (CLC) is an innovative method to oxidize fuels with inherent $\mathrm{CO}_{2}$ sequestration that uses well-established boiler technology similar to circulating-fluidized bed boilers (CFB). Because of those characteristics it could potentially play a significant role in achieving large reductions in global $\mathrm{CO}_{2}$ emissions, if used as an affordable technology for $\mathrm{CO}_{2}$ capture. Chemicallooping combustion utilizes two separate reactors, one air reactor (AR) and one fuel reactor (FR). A solid oxygen carrier $\left(\mathrm{MeO}_{\mathrm{x}} / \mathrm{MeO}_{\mathrm{x}-1}\right)$ performs the task of transporting oxygen between the reactors. Direct contact between fuel and air is avoided, see Fig. 1.

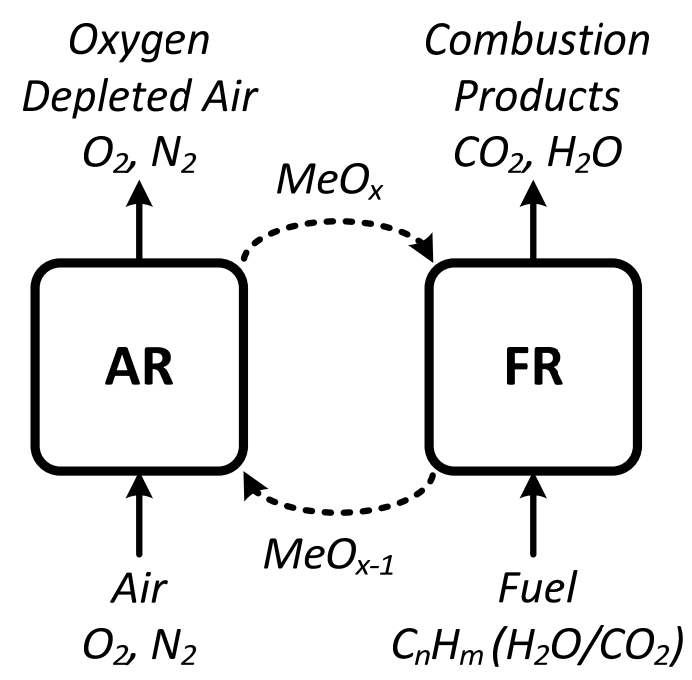

Fig. 1. Schematic description of chemical-looping combustion.

The oxygen carrier circulates between the two reactors. In the fuel reactor, it is reduced by the fuel, which in turn is oxidized to $\mathrm{CO}_{2}$ and $\mathrm{H}_{2} \mathrm{O}$ according to reaction (1). In the air reactor, it is oxidized to its initial state with $\mathrm{O}_{2}$ from the air according to reaction (2). Combining reaction (1) and reaction (2) yields reaction (3), which is complete combustion of the fuel with $\mathrm{O}_{2}$.

$$
\begin{aligned}
& \mathrm{C}_{\mathrm{n}} \mathrm{H}_{\mathrm{m}}+(2 \mathrm{n}+1 / 2 \mathrm{~m}) \mathrm{MeO}_{\mathrm{x}} \rightarrow \mathrm{nCO}_{2}+(1 / 2 \mathrm{~m}) \mathrm{H}_{2} \mathrm{O}+(2 \mathrm{n}+1 / 2 \mathrm{~m}) \mathrm{MeO}_{\mathrm{x}-1} \\
& \mathrm{MeO}_{1-\mathrm{x}}+1 / 2 \mathrm{O}_{2} \rightarrow \mathrm{MeO}_{\mathrm{x}} \\
& \mathrm{C}_{\mathrm{n}} \mathrm{H}_{\mathrm{m}}+(\mathrm{n}+1 / 4 \mathrm{~m}) \mathrm{O}_{2} \rightarrow \mathrm{nCO}_{2}+(1 / 2 \mathrm{~m}) \mathrm{H}_{2} \mathrm{O}
\end{aligned}
$$

In reaction (1), it was assumed that the fuel is in gas phase and that it reacts with the oxygen carrier in a gas-solid-reaction. However, with some oxygen carrier materials gas-phase $\mathrm{O}_{2}$ can be released directly in the fuel reactor according to reaction (4). 


$$
\mathrm{MeO}_{\mathrm{x}} \leftrightarrow \mathrm{MeO}_{1-\mathrm{x}}+1 / 2 \mathrm{O}_{2}
$$

The oxygen partial pressure is dependent upon the temperature and the oxide system used. If there is a fuel present it will react directly with released $\mathrm{O}_{2}$ according to reaction (3), which will facilitate further $\mathrm{O}_{2}$ release until all available fuel is consumed. The reduced oxygen carrier is then recirculated to the air reactor where it is reoxidized according to reaction (2). This reaction scheme is referred to as chemicallooping with oxygen uncoupling (CLOU).

Chemical-looping combustion has several attractive features. The gas from the fuel reactor consists essentially of $\mathrm{CO}_{2}$ and $\mathrm{H}_{2} \mathrm{O}$ so condensation of steam to liquid water is all that is needed to obtain almost pure $\mathrm{CO}_{2}$ for sequestration. In contrast to other technologies for $\mathrm{CO}_{2}$ capture such as absorption or adsorption of $\mathrm{CO}_{2}$ and oxyfuel combustion, there is no inherent cost or energy penalty for gas separation associated with chemical-looping combustion.

What constitutes a suitable reactor temperature may differ slightly between different oxygen carrier materials, but is usually considered to be in the range of $800-1050^{\circ} \mathrm{C}$. The most commonly proposed way to design a chemical-looping combustor is to use circulating fluidized beds with oxygen-carrier particles as bed material. This is straightforward technology currently used for example in circulating fluidized-bed boilers. The main difference is that the inert bed material used in conventional applications would need to be replaced with an active oxygen carrier in chemical-looping combustion. Commonly proposed oxygen carrier materials include transition metal oxides such as $\mathrm{NiO}, \mathrm{Fe}_{2} \mathrm{O}_{3}, \mathrm{CuO}$ or $\mathrm{Mn}_{3} \mathrm{O}_{4}$, with or without inert support materials such as for example $\mathrm{Al}_{2} \mathrm{O}_{3}$ or $\mathrm{ZrO}_{2}$.

The interest in chemical-looping combustion and related technologies has increased steadily during the past decade, and it is not possible to provide an overview in this publication. Therefore the interested reader is referred to recent review articles by Lyngfelt \& Mattisson [3] and Adanez et al. [4].

\subsection{Heavy Oils}

The term heavy oil is somewhat ambiguous and may include fuels of quite different properties and origin. It can include both heavy residual oil fractions left over from refining of light crude oil and heavy crudes, such the oil of the Orinoco River in Venezuela or the Athabasca oil sands in Canada. Related terms are asphalt and bitumen, of which the former is commonly used for the product used as glue during road construction and the latter is the preferred geological term for naturally occurring resources of heavy petroleum.

Regardless of origin, all heavy oils are characterized by very high viscosity and very high boiling point. At room temperature these kinds of oils are almost solid. It is possible to dramatically reduce the viscosity of heavy oils by heating and mixing with small amounts of light hydrocarbons though. Such treatment yields fuels which flow effortlessly and are simpler to use for combustion purposes. Depending on the origin such fuels may contain high concentrations of sulfur and other impurities such as heavy metals, which could have important effects on the conversion process.

The interest in using different kinds of heavy oils as fuel and feedstock for industrial applications has increased lately. This is not surprising considering the currently high price and somewhat limited supply of light crude oil. Chemical-looping combustion may provide an opportunity to process these kinds of fuels with inherent $\mathrm{CO}_{2}$ capture, which could provide considerable environmental benefits or $\mathrm{CO}_{2}$ suitable for applications such as enhanced oil recovery.

\subsection{Liquid Fuels and Chemical-Looping Combustion}

Current research with respect to chemical-looping combustion has been focusing on gaseous and solid fuels such as natural gas and coal. The use of heavy oil as fuel in chemical-looping combustion has been examined in a small number of studies. Cao et al. [5] gasified bitumen and asphalt in a separate pyrolysis 
unit before feeding the obtained synthesis gas to a batch fluidized-bed reactor. Hoteit et al. [6] conducted chemical-looping combustion experiments in which a domestic fuel oil and a heavy fuel oil were injected into a batch fluidized-bed reactor with a nickel-based oxygen carrier. Other groups having reported work with liquid fuels in processes related to chemical-looping combustion includes Pimenidou et al. [7] who used waste cooking oil in a batch packed bed reactor in order to produce synthesis gas, and Mendiara et al. [8] who investigated tar reforming with different oxygen carriers by feeding nitrogen saturated with toluene into a batch fixed-bed reactor. Also production of hydrogen from different pyrolysis oils and waste oils by injection into packed-bed reactor has been examined by Lea-Langton et al. [9] and Giannakeas et al. [10]. The contribution to the field by the authors of this paper will be explained in section 4 below.

\section{Project Description}

\subsection{Project Phases}

The project is divided into four separate phases. Phase I involves design and construction of a system capable of feeding liquid fuels to an existing $300 \mathrm{~W}$ chemical-looping combustion reactor in order to provide proof of concept. Phase II involves design and construction of an improved version of the $300 \mathrm{~W}$ reactor and operation of said reactor with a number of oxygen carrier materials using non-sulfurous and sulfurous kerosene as fuel. Phase III involves redesign and modification of an existing $10 \mathrm{~kW}$ chemicallooping combustion reactor and operation of said reactor with two oxygen carrier materials chosen among the ones examined in phase II. The fuel will initially be ordinary fuel oil in order to validate the chosen injection system, and later switched to a heavy vacuum residue (HVR) which is a very heavy residual oil produced during refining of crude oil. Finally, Phase IV involves a techno-economic evaluation of chemical-looping combustion of heavy fuel oils. The basis for the evaluation will be experimental data and experience from phase I-III, as well as current state-of-the-art knowledge about circulating fluidizedbed boilers.

\subsection{Key Challenges}

The project involves a number of interesting challenges that need to be addressed. The most important challenges when using heavy fuel oil as fuel in chemical-looping combustion are expected to be:

- Injection and vaporization of fuel directly into a bubbling fluidized bed. This is likely a considerable challenge. Vaporization prior to injection is unfeasible due to the very high boiling point of heavy oils, since thermal decomposition and char formation could be expected to take place prior to complete vaporization. Achieving good mixing between fuel and solids may also be challenging.

- High sulfur content of fuel. Heavy fuel oils often have very high sulfur content. This is true also for heavy vacuum residues and could be expected have a negative effect on oxygen carrier materials containing elements such as example nickel, calcium or magnesium. Inertness towards sulfur is likely to be one of the more important characteristics of oxygen carrier particles for this application.

- Trace metals in the fuel. Heavy fuel oils can also contain substantial amounts of trace metals, including well-known catalyst poisons such as vanadium. This may or may not be a problem, and remains to be examined.

\section{Results}

As of this moment, phase I and phase II of the project have been successfully executed. In phase I of the project an injection system capable of feeding light liquid fuels into an existing chemical-looping 
reactor was designed and successfully operated for $54 \mathrm{~h}$ with fuel addition. The reactor was an existing $300 \mathrm{~W}$ chemical-looping combustor previously used for gaseous fuels. A NiO-based oxygen carrier and sulfur-free kerosene was used and the intent was to provide proof of concept, both for continuous chemical-looping combustion of liquid fuels and of synthesis gas generation by chemical-looping reforming of liquid fuels. In the combustion experiments $95-99 \%$ of the fuel carbon was converted to $\mathrm{CO}_{2}$ and only a minute amount of hydrocarbons was detected in the off-gas. For the reforming experiments, synthesis gas was produced with concentrations of hydrocarbons as low as $0.01 \%$. The operating principle of the resulting injection system is described in Fig. 2. For details about this particular experimental campaign see Moldenhauer et al. [11].

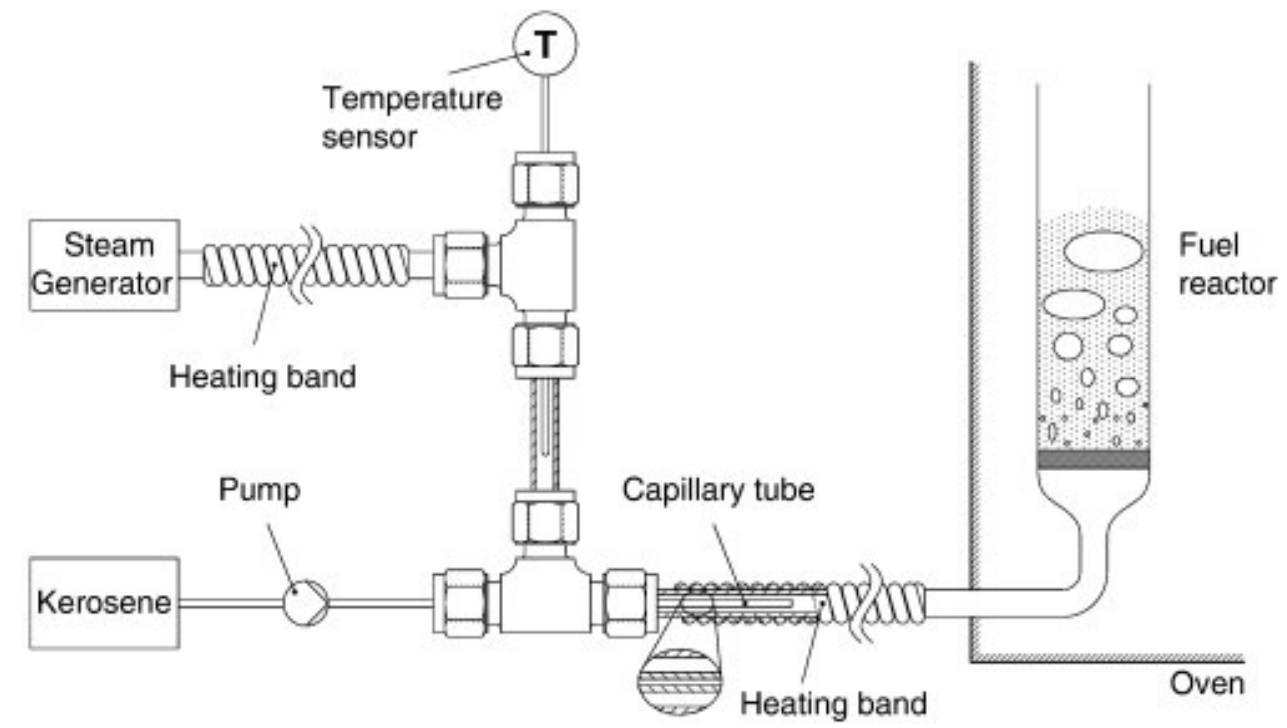

Fig. 2. Schematic description of the fuel feeding system of the $300 \mathrm{~W}$ reactor. Kerosene is vaporized in the capillary tube with heat provided by steam and a heating band and fed to the reactor in gas phase

In phase II of the project, an improved version of an existing $300 \mathrm{~W}$ reactor was designed and constructed. The new reactor, which is shown in Fig. 3 on the following page, was made higher in order to increase flexibility with respect to solids inventory. The downcomer and the slot section, located between the reactor parts, were made deeper and higher. The slot and downcomer basically are fluidized gas-tight loop seals, but in practice minor leakage between the reactors parts is usually observed.

In the first experimental campaign the new reactor was operated with $\mathrm{Mn}_{3} \mathrm{O}_{4}$-based oxygen-carrier particles for $17 \mathrm{~h}$ achieving more than $99 \%$ conversion of fuel carbon to $\mathrm{CO}_{2}$, using sulfur-free kerosene as fuel. These promising results were followed up by operating the reactor with $\mathrm{CuO}$-based oxygencarrier particles for $45 \mathrm{~h}$, achieving practically $100 \%$ fuel conversion already at $900^{\circ} \mathrm{C}$. $\mathrm{CuO}$ has the ability to release gas-phase $\mathrm{O}_{2}$ according to reaction (4), which clearly facilitates complete fuel conversion. This oxygen release was clearly seen during experiments designed to elucidate this CLOU behavior, and the oxygen concentration in the fuel reactor varied between $\approx 0.5 \%$ and $\approx 8.0 \%$ in the temperature interval $850^{\circ} \mathrm{C}$ and $975^{\circ} \mathrm{C}$ when the fuel reactor was fluidized with argon. The manganesebased oxygen carrier had a tendency to break apart and form fines, while the copper-based materials appeared to have acceptable integrity and mechanical properties. For details about these two experimental campaigns, see Moldenhauer et al. [12]. 


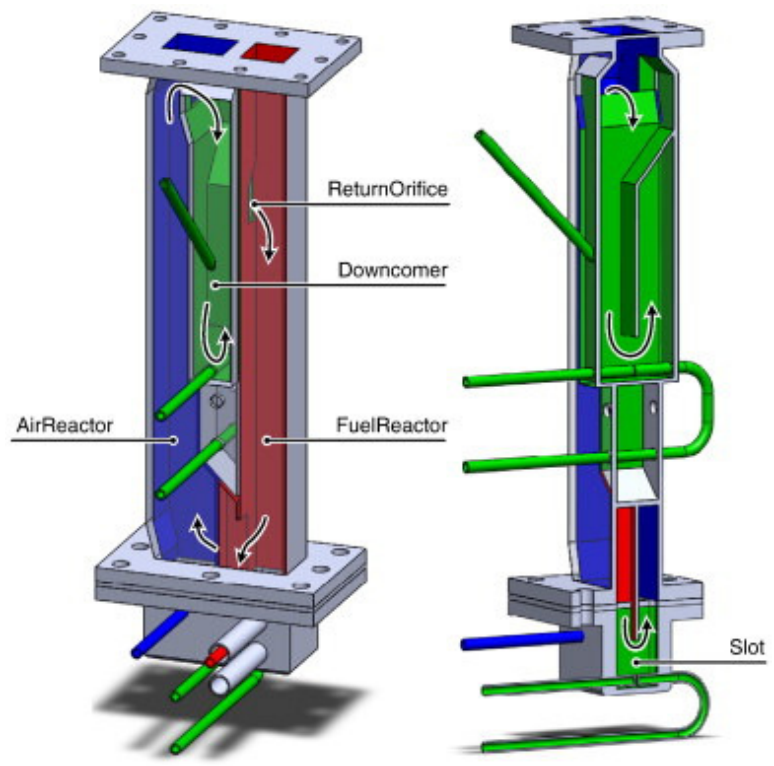

Fig. 3. Schematic three-dimensional illustration of the improved $300 \mathrm{~W}$ laboratory reactor. It is constructed in one piece divided in two parts by a downcomer-slot-section fluidized with argon, preventing gas leakage between the air and fuel reactor parts. During operating the reactor is filled roughly $\approx 1 / 4(300-450 \mathrm{~g})$ with oxygen carrier particles in the size range $90-212 \mu \mathrm{m}$.

Further work within phase II involved operation with the mineral ilmenite $(\approx \mathrm{FeTiO} 3)$ as oxygen carrier, using both sulfur-free and sulfur-rich kerosene. The total operation time was $80 \mathrm{~h}$ and up to $99 \%$ conversion of fuel carbon into $\mathrm{CO}_{2}$ was achieved. No negative effect of fuel sulfur was observed. In fact, conversion of the slightly heavier sulfurous kerosene appears to have had a positive effect on the fuel conversion. For details about the experimental campaigns involving ilmenite as oxygen carrier, see Moldenhauer et al. [13]. A summary of the results obtained in phase II of the project can be found in Fig. 4.
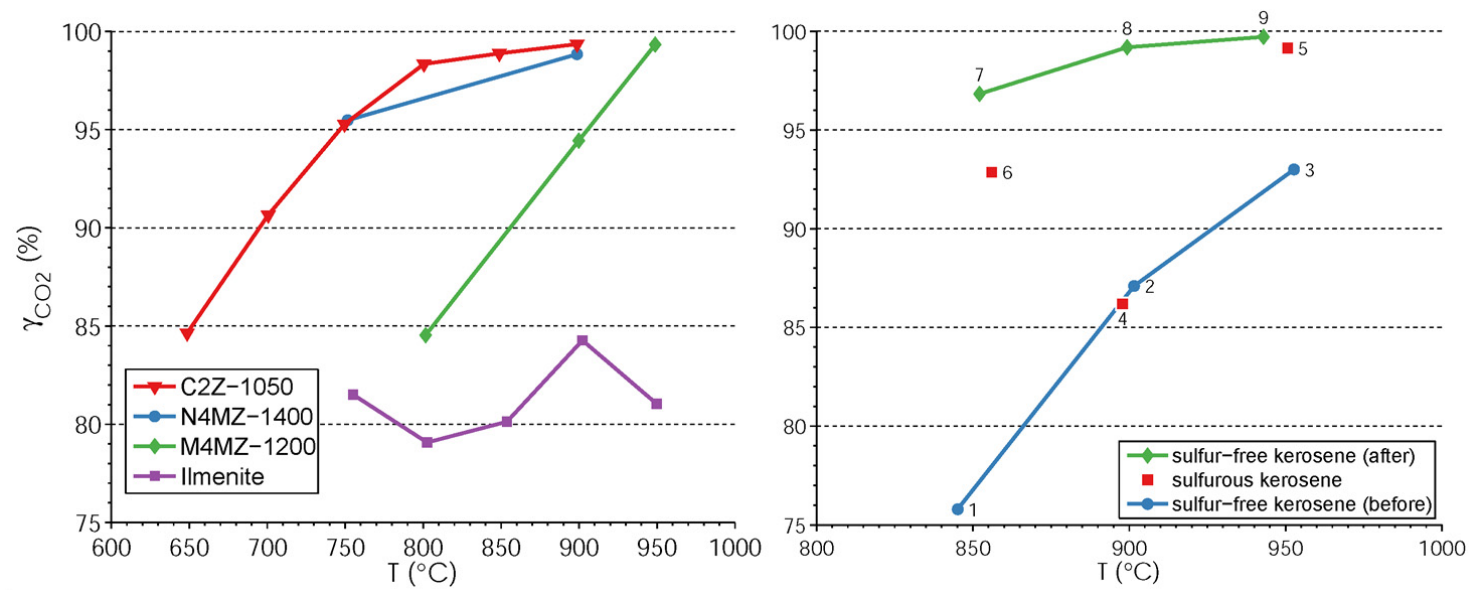

Fig. 4. Conversion of fuel carbon to $\mathrm{CO}_{2}\left(\gamma_{\mathrm{CO} 2}\right)$ as function of temperature (T) for the different oxygen carrier materials and fuels used in the studies by Moldenhauer et al. [10-12] cited above. In Fig 4a the notations are as follows: CSZ-1050: 20 wt\% CuO with $\mathrm{ZrO}_{2}, \mathrm{~N} 4 \mathrm{MZ}: 40 \mathrm{wt} \% \mathrm{NiO}$ with $\mathrm{Mg}-\mathrm{ZrO}_{2}, \mathrm{M} 4 \mathrm{MZ}-1200: 40 \mathrm{wt} \% \mathrm{Mn}_{3} \mathrm{O}_{4}$ with $\mathrm{Mg}-\mathrm{ZrO}_{2}$. Figure $4 \mathrm{~b}$ is for ilmenite with and without sulfurous fuel. All data is for operation with the thermal effect of $144 \mathrm{~W}$. 
In Fig. 4, The $\mathrm{CO}_{2}$ yield is expressed as the molar flow of $\mathrm{CO}_{2}$ that leaves the fuel reactor divided by the sum of all carbon that leaves the fuel reactor, which be rewritten with concentrations $\left(y_{i}\right)$ instead of molar flows as is done in equation 5. (4).

$$
\gamma_{\mathrm{CO} 2}=\frac{y_{\mathrm{CO} 2, \mathrm{FR}}}{y_{\mathrm{CO} 2, \mathrm{FR}}+y_{\mathrm{CO}, \mathrm{FR}}+\sum_{m=1}^{9}\left(m \cdot y_{\mathrm{C} m \mathrm{Hn}, \mathrm{FR}}\right)}
$$

It can be seen that increased temperature typically resulted in better fuel conversion. The manganesebased oxygen carrier was much more sensitive to temperature than compared to the nickel- and copperbased particles. It can also be seen that results obtained with ilmenite as oxygen carrier were less predictable. The reason for this is probably the well-documented ability of ilmenite to become more porous following repeated oxidation and reduction reactions, see for example Rydén et al. [14] or Moldenhauer et al. [15]. This behavior is associated with migration of $\mathrm{Fe}_{2} \mathrm{O}_{3}$ to the particle surface and increased reactivity with hydrocarbons or other reducing gases, see Cuadrat et al. [16]. In a separate study of the effect of sulfur on the reactivity with ilmenite, see Fig 4b, a drastic improvement in fuel conversion was seen in the particle reactivity after experiments with a kerosene containing sulfur, suggesting the sulfurous compounds in some way affect the particle structure, possibly accelerating the process outlined above.

\subsection{Related Results}

In addition to the main project, there has also been a project amendment which involved manufacturing of oxygen-carrier particles from Saudi Aramco black powder, a waste material from pipelines consisting mainly of iron oxide. Such material has been examined as is, and also as spray dried or freeze granulated into particles with or without addition of $\mathrm{Mn}_{3} \mathrm{O}_{4}$ or Brazilian manganese ore. This study revealed that black powder could have similar or higher reactivity as the reference material ilmenite. These findings were obtained from a lab-scale batch reactor using samples of $15 \mathrm{~g}$. Mixing black powder with a Brazilian Mn-ore resulted in oxygen carriers capable of releasing small amount of gas phase $\mathrm{O}_{2}$ by forming combined iron-manganese oxides. The principles behind such combined oxide oxygen carriers have previously been outlined by Azimi et al. [17] and Rydén et al. [18].

\section{Conclusions and Future Outlook}

Work conducted in phase I and phase II of the project has clearly demonstrated that chemical-looping combustion of liquid hydrocarbons is feasible. All examined oxygen carrier materials were capable of achieving very high conversion of hydrocarbons into $\mathrm{CO}_{2}$ at certain conditions. Chemical-looing reforming to synthesis gas of liquid fuel to synthesis gas has also been demonstrated in the continous CLC unit.

Phase III and phase IV will demonstrate whether direct feeding of heavy feedstock into a bubbling fluidized bed will be a possibility, as well as the economic potential of the concept as a whole. As of this moment, the fuel reactor of the $10 \mathrm{~kW}$ reactor and a method for direct fuel injection has been designed and constructed. Commissioning of the reactor system as a whole is currently on-going

\section{Acknowledgements}

This paper was produced in the project "Chemical-looping with liquid hydrocarbon fuels" financed by Saudi Aramco. 


\section{References}

[1] Intergovernmental Panel on Climate Change. Carbon dioxide Capture and Storage. Cambridge: Cambridge University Press; 2005.

[2] Liu H, Tellez BC, Atallah T, Barghouty M. The role of $\mathrm{CO}_{2}$ capture and storage in Saudi Arabia's energy future. International Journal of Greenhouse Gas Control 2012; 11: 163-171.

[3] Lyngfelt A, Mattisson T. Materials for chemical-looping combustion. In: Stolten D, Sherer V, editors. Efficient Carbon Capture for Coal Power Plants, Weinheim: WILEY-VCH Verlag GmbH \& Co; 2011.

[4] Adanez J, Abad A, Garcia-Labiano F, Gayán P, De Diego LF. Progress in chemical-looping combustion and reforming technologies. Progress in Energy and Combustion Science 2012;38:215-282.

[5] Cao Y, Lia B, Zhao HY, Lin CW, Sit SP, Pan WP. Investigation of Asphalt (Bitumen)-fuelled Chemical Looping Combustion using Durable Copper-based Oxygen Carrier., Energy Procedia 2011;4:457-464.

[6] Hoteit A, Forret A, Pelletant W, Roesler J, Gauthier T. Chemical Looping Combustion with Different Types of Liquid Fuels. Oil \& Gas Science and Technology 2011;66:193-199.

[7] Pimenidou P, Rickett G, Dupont V, Twigg MV. Chemical looping reforming of waste cooking oil in packed bed reactor. Bioresource Technology 2011;101;6389-6397.

[8] Mendiara T, Johansen JM, Utrilla R, Geraldo P, Jensen AD, Glarborg P. Evaluation of different oxygen carriers for biomass tar reforming (I): Carbon deposition in experiments with toluene, Fuel 2011; 90: 1049-1060 .

[9] Lea-Langton A, Zin RM, Dupont V, Twigg MV. Biomass pyrolysis oils for hydrogen production using chemical looping reforming, International Journal of Hydrogen Energy 2012;37: 2037-2043.

[10] Giannakeas N, Lea-Langton A, Dupont V, Twigg MV. Hydrogen from Scrap Tyre Oil via Steam Reforming and Chemical Looping in a Packed Bed Reactor.Applied Catalysis B: Environmental 2012;126: 249-257.

[11] Moldenhauer P, Rydén M, Mattisson T, Lyngfelt A. Chemical-looping combustion and chemical-looping reforming of kerosene in a circulating 300W laboratory reactor. International Journal of Greenhouse Gas Control 2012; 9: 1-9.

[12] Moldenhauer P, Rydén M, Mattisson T, Lyngfelt A. Chemical-Looping Combustion and Chemical-Looping with Oxygen Uncoupling of Kerosene with Mn- and Cu-based Oxygen Carriers in a Circulating Fluidized Bed 300W Laboratory Reactor. Fuel Processing Technology 2012; DOI 10.1016/j.fuproc.2012.06.013.

[13] Moldenhauer P, Rydén M, Mattisson T, Younes M, Lyngfelt A. The use of ilmenite as oxygen carrier with kerosene in a 300W CLC laboratory reactor with continuous circulation. In: Proceedings of $2^{\text {nd }}$ International Conference on Chemical Looping, Darmstadt, Germany, 25-27 September 2012.

[14] Rydén M, Johansson M, Cleverstam E, Lyngfelt A, Mattisson, T. Ilmenite with addition of NiO as oxygen carrier for chemical-looping combustion. Fuel 2010;89:3523-3533.

[15] Moldenhauer P, Rydén M, Lyngfelt A. Testing of minerals and industrial by-products as oxygen carriers for chemicallooping combustion in a circulating 300W laboratory reactor. Fuel 2012; 93: 351-363.

[16] Cuadrat A, Abad A, Adánez J, de Diego LF, García-Labiano F, Gayán P.Behavior of ilmenite as oxygen carrier in chemical-looping combustion. Fuel Processing Technology 2012;94:101-112.

[17] Azimi G, Rydén M, Leion, H, Lyngfelt A, Mattisson T. $\left(\mathrm{Mn}_{\mathrm{z}} \mathrm{Fe}_{1-\mathrm{z}}\right)_{\mathrm{y}} \mathrm{O}_{\mathrm{x}}$ combined oxides as oxygen carrier for ChemicalLooping with Oxygen Uncoupling (CLOU). AIChE Journal 2012; DOI 10.1002/aic.13847

[18] Rydén M, Leion H, Mattisson T, Lyngfelt A. Combined oxides as oxygen carrier material for chemical-looping with oxygen uncoupling. In: Proceedings of $2^{\text {nd }}$ International Conference on Chemical Looping, Darmstadt, Germany, 25-27 September 2012. 